\title{
Ultra-low-dose oral contraceptive pill: a new approach to a conventional requirement
}

\author{
Meenakshi Ahuja1, Pramod Pujari2*
}

\begin{abstract}
${ }^{1}$ Senior Consultant Obstetrician and Gynecologist, Max Super Specialty Hospital, Saket, New Delhi, India
${ }^{2}$ Medical Advisor, Pfizer limited, Mumbai, Maharashtra, India
\end{abstract}

Received: 05 December 2016

Accepted: 17 December 2016

*Correspondence:

Dr. Pramod Pujari,

E-mail: pramodpujari7@gmail.com

Copyright: () the author(s), publisher and licensee Medip Academy. This is an open-access article distributed under the terms of the Creative Commons Attribution Non-Commercial License, which permits unrestricted non-commercial use, distribution, and reproduction in any medium, provided the original work is properly cited.

\begin{abstract}
Combined oral contraceptives (COCs) offer a convenient, safe, effective, and reversible method of contraception. However, their use is limited by side effects. Several strategies have been suggested to make COC use more acceptable among women. Reduction in the dose of estrogen is a commonly accepted approach to reduce the side effects of COC. Use of newer generation of progestins, such as gestodene, reduces the androgenic side effects generally associated with progestogens. Furthermore, reduction in hormone-free interval, as a 24/4 regimen, can reduce the risk of escape ovulation (hence preventing contraceptive failure) and breakthrough bleeding. It also reduces hormonal fluctuations, thereby reducing the withdrawal symptoms. A COC with gestodene $60 \mu \mathrm{g}$ and ethinylestradiol (EE) $15 \mu \mathrm{g}$ offers the lowest hormonal dose in 24/4 treatment regimen. This regimen has been shown to offer good contraceptive efficacy and cycle control. With the progress of treatment cycles, the incidence of breakthrough bleeding reduces. Gestodene/EE low dose 24/4 regimen was associated with lower incidence of estrogen-related adverse events, such as headache, breast tenderness, and nausea. Furthermore, COCs containing low dose of estrogen have not been associated with any adverse effect on haemostasis in healthy women. Ultra-low-dose COCs can be considered in women who are at risk of developing estrogen-related side effects.
\end{abstract}

Keywords: Combined oral contraceptive, Gestodene, Ethinylestradiol, Ultra-low dose contraceptive, 24/4 regimen

\section{INTRODUCTION}

The era of oral contraception began in 1960s, with the availability of the first COC (comprising progestin and estrogen), commonly known as the "pill." The COC inhibits ovulation and implantation, thereby preventing pregnancy. Progestins prevent ovulation, mediated by negative feedback mechanism resulting in a decrease in luteinizing hormone (LH). Progestin also reduces cervical mucus receptivity of the sperm and endometrial thickness. Estrogen contributes to the antiovulatory mechanism of COCs by suppressing both follicle stimulating hormones (FSH) and LH. It also helps in stabilizing the endometrium, thus providing better cycle control. ${ }^{1}$
Ever since its availability, the COC has been used by millions of women across the world as a convenient, safe, effective, and reversible method of contraception. ${ }^{1}$ Recent estimates suggest that $9 \%$ of women in reproductive age across the world use the pill. It is the most common method of contraception in industrialised countries and the third most common method of contraception in developing countries. ${ }^{2}$

The patterns of contraceptive use have been evaluated in the National Family Health Survey-3 (NFHS-3). Despite $85 \%$ of surveyed women agreeing to know about the pill, the use of the pill was low; only $3.1 \%$ of married women use the pill. ${ }^{3}$ The principal reason given by COC users for discontinuing the method is side effects. ${ }^{4}$ 


\section{Milestones in the Evolution of COCs}

Due to the higher concentrations of estrogens and progestins, early COCs were often associated with intolerable side effects, including irregular bleeding, nausea, headache, weight gain, and episodes of venous thromboembolism. ${ }^{2}$ Discontinuation of contraceptive methods remains a major challenge for family planning program managers. According to the NFHS-3 data, despite lower failure rates $(3 \%)$, discontinuation rate for pills was 49\%; the most common reason for discontinuation was the concern about side effects or health problems. ${ }^{3}$

Accordingly, attempts have been made to reduce the side effects of COCs, which involved modifications of hormone doses and types, dosage regimens, and administration schedules. The evolutionary steps undergone by COCs over the past half century have been summarised in Table $1 .{ }^{1}$

Reduction in the dose of estrogens has been a significant modification in the evolution of COCs. This was done with the intention of improving the safety and tolerability profile of COCs without compromising its effectiveness. ${ }^{1}$ While earlier generations of COCs have up to $150 \mu \mathrm{g}$ of estrogen, the modern pills have $20 \mu \mathrm{g}$ (low-dose COC) or $15 \mu \mathrm{g}$ (ultra-low-dose COC) of estrogen. Ultra-low-dose COCs have the lowest dose of estrogen $(15 \mu \mathrm{g})$ and have been approved in Eastern countries and in India. ${ }^{5}$ However, the low doses of estrogen used in modern low- and ultra-low-dose COCs are inadequate to produce a consistent antiovulatory effect. Thus, the focus has shifted to the progestin component, which contributes to the majority of antiovulatory effects of COCs. ${ }^{6}$

\section{PROGESTINS}

Based on the time of introduction, the progestins have been classified into four generations, as shown in Table $2 .^{7}$

Progesterone is the only natural type of progesterone. A broad spectrum of synthetic progestins have been prepared from different parent compounds. ${ }^{8}$ Depending on its chemical structure, the biological activity of a progestogen changes considerably. ${ }^{8}$

It has been known that effects of progestins are not only dependent on its interaction with progesterone receptors but also with other steroid hormone receptors, including androgen receptors, estrogen receptors, glucocorticoid receptors, or mineralocorticoid receptors. While all progestins bind to progesterone receptors, each progestin has a distinctive profile of affinity for other receptors, which might not be shared even among the other members of the same class. ${ }^{6}$ With such varied affinities, it is now possible to select a progestin to suit an individual patient (Table 3$).^{2}$
Levonorgestrel has no estrogenic but strong antiestrogenic activity, along with no mineralocorticoid and glucocorticoid activities. Drospirenone has strong progestogenic activity, along with anti-aldosterone activity and natriuretic effect. It also has strong antimineralocorticoid activity. ${ }^{2}$

Since the earlier progestins were specifically designed for their contraceptive use, they primary had antigonadotropic activity. Later, the focus was shifted toward creating an "ideal" progestin, with potent progestational and antiestrogenic actions on the endometrium, a strong antigonadotropic effect, but without any androgenic or glucocorticoid effects. This was expected to offer the benefits of progesterone without undesirable effects, such as causing acne, a decrease in high-density lipoprotein cholesterol, bloating, and water retention. ${ }^{6}$

\section{A focus on Gestodene}

In order to minimise the androgenic effects, progestins such as gestodene, desogestrel, and norgestimate were introduced. Gestodene, a 19-nortestosterone derivative, is a widely-used progestin. Structurally, gestodene has an additional double bond between $\mathrm{C}-15$ and $\mathrm{C}-16$ in the Dring to levonorgestrel. This double bond leads to a conformational change in the 18-ethyl group, affecting the pharmacokinetics of the molecule. The androgenic affinity of gestodene is twice as that of levonorgestrel; however, the progestational to androgenic effect ratio of gestodene remains higher than that of levonorgestrel. Gestodene, unlike desogestrel and norgestimate, is not a prodrug. Furthermore, with a higher affinity for sexhormone binding globulin, gestodene has a lower metabolic clearance rate and a greater concentration in the circulation. This aspect may be particularly beneficial in case of missed pills. Furthermore, the longer half-life and an alternative regimen (24/4 regimen, which will be discussed later) contribute to the reduction in failure rate of COCs. ${ }^{9}$

\section{A new approach to reducing hormone free interval: The 24/4 regimen}

\section{The classical 21/7 regimen}

Since the time of availability, the COCs have been offered as a 21/7 regimen, which involves 21 days of active treatment, followed by a 7-day hormone-free interval (HFI), when a withdrawal bleed usually occurs. Classically, this regimen was used in an attempt to mimic the natural monthly menstrual cycle in women, improving the general acceptance. This also reduced the concerns of not having bled on a monthly basis and also provided an assurance of not being pregnant. ${ }^{10,11}$

However, it has been suggested that the $21 / 7$ regimen has its own sets of concerns. ${ }^{11}$ Evidence suggests that $21 / 7$ COC regimens might not adequately suppress ovarian 
activity and follicular development. ${ }^{10}$ With the current low-dose pills, endometrial sloughing begins within 2 days of the last active pill. The ovarian follicular recruitment begins much earlier in HFI, making escape ovulation more likely. ${ }^{12}$ The problem is substantial with a missed or late start of the next COC pill cycle, consequently resulting in contraceptive failure. ${ }^{11}$
Another major problem is that the pill-free interval allows recurrence of withdrawal symptoms, such as headache, acne, and premenstrual symptoms, which are otherwise controlled by active pills. ${ }^{11}$

Table 1: Evolution of COC. ${ }^{1}$

\begin{tabular}{|c|c|}
\hline Decades & Milestones \\
\hline \multirow{2}{*}{ 1960s } & Introduction of first oral contraceptives in Europe and Australia \\
\hline & In Europe, pill was only recommended for regulating menstrual disorders and in married women. \\
\hline \multirow{2}{*}{ 1970s } & Introduction of 'mini pill' (progestin only pill) \\
\hline & Publication of initial reports of use of COC and thromboembolic events \\
\hline \multirow{3}{*}{ 1980s } & Introduction of biphasic and triphasic pills \\
\hline & Reduction in use of high dose estrogen containing pills \\
\hline & $\begin{array}{l}\text { Recognition of other health benefits and fact that health benefits of COC outweigh the possible health risks } \\
\text { in nonsmoking women over } 40 \text { years }\end{array}$ \\
\hline 1990s & Introduction of low dose COCs \\
\hline \multirow{3}{*}{ 2000s } & Introduction of extended and continuous regimen COCs \\
\hline & Development and introduction of newer progestins \\
\hline & Introduction of non-oral combined hormonal contraceptives preparations \\
\hline \multirow{3}{*}{ 2010s } & Use of natural estrogens in $\mathrm{COC}$ regimens \\
\hline & Further investigations on newer progestins \\
\hline & Investigation on genetic and proteonomic targets for contraception \\
\hline
\end{tabular}

Table 2: Classification of progestins on the basis of time of introduction. ${ }^{7}$

\begin{tabular}{|c|c|c|c|}
\hline First generation & Second generation & Third generation & Newer progestins \\
\hline $\begin{array}{l}\text { Pregnanes } \\
\text { Chlormadinone acetate } \\
\text { Cyproterone acetate } \\
\text { Megestrol acetate } \\
\text { Estranes } \\
\text { Noerethindrone } \\
\text { norethindrone acetate } \\
\text { Ethynodiol diacetate } \\
\text { Lynestranol } \\
\text { Norethynodrel }\end{array}$ & $\begin{array}{l}\text { Dl-norgestrel } \\
\text { Levonorgestrel }\end{array}$ & $\begin{array}{l}\text { Desogestrel } \\
\text { Norgestimate } \\
\text { Gestodene }\end{array}$ & $\begin{array}{l}19 \text { nor-progesterones } \\
\text { Promegestone } \\
\text { Trimegestone } \\
\text { Demegestone } \\
\text { Nesterone } \\
\text { Nomegestrol acetate } \\
\text { Gonanes } \\
\text { Norelgestromine } \\
\text { Etonogestrel } \\
\text { Estranes } \\
\text { Dienogest } \\
\text { (non-ethylated) } \\
\text { Spironolactone } \\
\text { derivative } \\
\text { Drospirenone }\end{array}$ \\
\hline
\end{tabular}

\section{The 24/4 approach}

In order to avoid the limitations of the 7-day HFI, alternative approaches to the traditional $21 / 7$ regimen have been explored. One of these options has been to reduce the HFI with extended or continuous regimens. A $24 / 4$ regimen, involving a dosing regimen of 24 days of active treatment followed by four days of inactive pills, was introduced as a means to reduce the HFI. ${ }^{11}$ There are several advantages of shortening the HFI, some of which are discussed below:

\section{Reduction in risk of escape ovulation}

During the HFI, there is significant activation of the pituitary-ovarian axis, allowing at least some ovarian 
follicular growth that could lead to ovulation. Missing the pills will further extend the HFI, posing higher risk of escape ovulation and possible pregnancy. ${ }^{12}$ A study conducted by Wills et al. has shown that a reduction in HFI from 7 to 4 or 3 days leads to lower peaks in the gonadotropin and ovarian hormones (Figure 1). ${ }^{13}$ The
24/4 dosing regimen offers greater pituitary-ovarian inhibition, and thus, a lower risk of ovulation and cyst formation, as well as the potential for lower incidence of common hormone-withdrawal symptoms compared to standard $21 / 7$ dosing. ${ }^{12}$

Table 3: Effects of different progestins ${ }^{\cdot 2}$

\begin{tabular}{|lllll|} 
& $\begin{array}{l}\text { Anti-estrogenic } \\
\text { activity }\end{array}$ & $\begin{array}{l}\text { Androgenic } \\
\text { activity }\end{array}$ & $\begin{array}{l}\text { Anti-androgenic } \\
\text { activity }\end{array}$ & $\begin{array}{l}\text { Anti-mineralocorticoid } \\
\text { activity }\end{array}$ \\
\hline Progesteron & + & - & + & + \\
\hline Levonorgestrel & + & + & - & - \\
\hline Gestodene & + & + & - & + \\
\hline Desogestrel & + & + & + & - \\
\hline Cyproterone & + & - & + & + \\
\hline Desonorgestrel & + & - & + & - \\
\hline
\end{tabular}

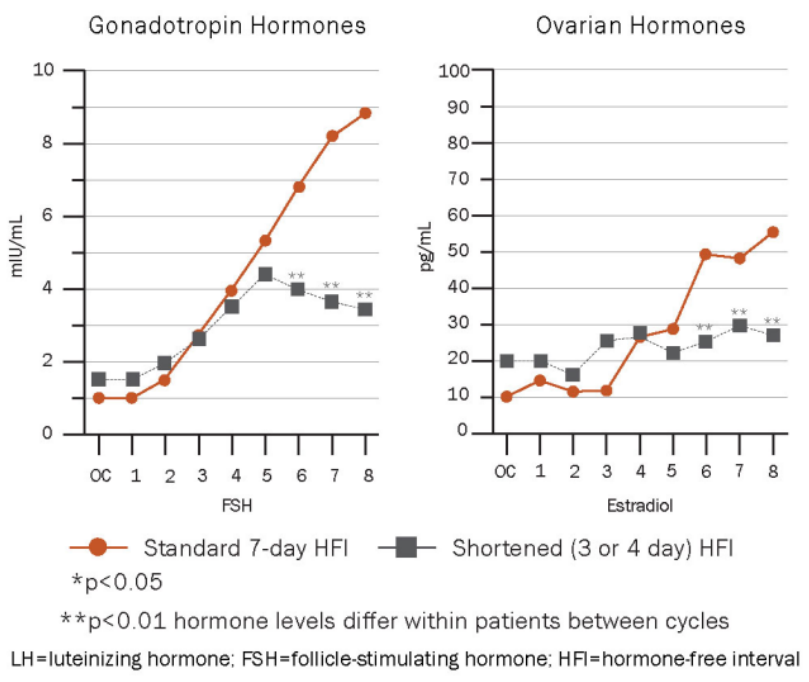

Figure 1: Levels of gonadotropin and ovarian hormones increase significantly during the HFI with conventional 21/7 dosing, but are blunted when the

HFI is shortened to a length of 3 or $\mathbf{4}$ days.

A randomised, double-blind study (Klippling et al.) compared ovarian activity with the use of COC containing EE/drospirenone $(20 \mu \mathrm{g} / 3.0 \mathrm{mg})$ in $21 / 7$ and $24 / 4$ regimens for three treatment cycles. It was reported that by the second cycle of treatment, ovulation and luteinized unruptured follicle had occurred in 1 woman each in the conventional $21 / 7$ group and none in the 24/4 regimen. Furthermore, with the intentional missing of three pills at the beginning of cycle 3 , the ovarian activity was less in the 24/4 regimen (one woman of 52 women who ovulated) compared with the $21 / 7$ regimen (four women of 52 women who ovulated). ${ }^{14}$ It has been reported that with 21/7 regimen, the follicular growth during HFI may become suitable for preferential growth and eventually ovulation. Prolongation of HFI, due to missed pills, may further increase the risk of follicular maturation and escape ovulation. ${ }^{15}$ Clinically, compared with 21/7 regimen, shortening the HFI with 24/4 regimen may increase the contraceptive safety margin when pills are omitted or missed. ${ }^{12}$

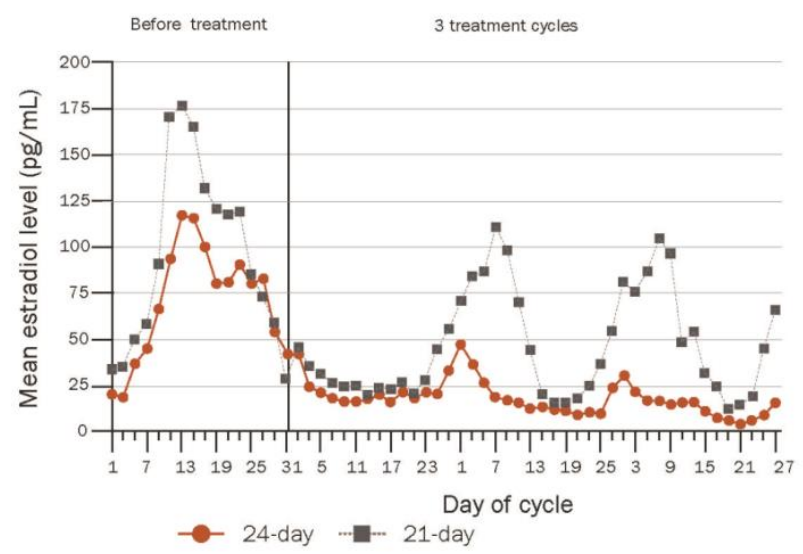

Figure 2: Mean serum 17-beta E2 concentration with 21- and 24- regimens.

\section{Minimise hormonal fluctuations}

Fluctuating hormone levels have been considered to contribute toward premenstrual symptoms that commonly occur during HFI. ${ }^{12}$ It has been shown that with use of COC containing gestodene/EE $(60 / 15 \mu \mathrm{g})$ over three treatment cycles, there were lower fluctuations in 17- $\beta$ E2 levels with 24/4 regimen, compared with 21/7 regimen (Figure 2). ${ }^{16}$

It has been reported that up to $70 \%$ of women on $21 / 7$ COC regimen experienced hormone-withdrawal symptoms during the HFI, such as nausea, vomiting, breast tenderness, bloating, swelling, headaches, 
unscheduled bleeding and spotting, and mood changes. Reducing the HFI was shown to improve the quality of life in $82 \%$ of women. ${ }^{17}$

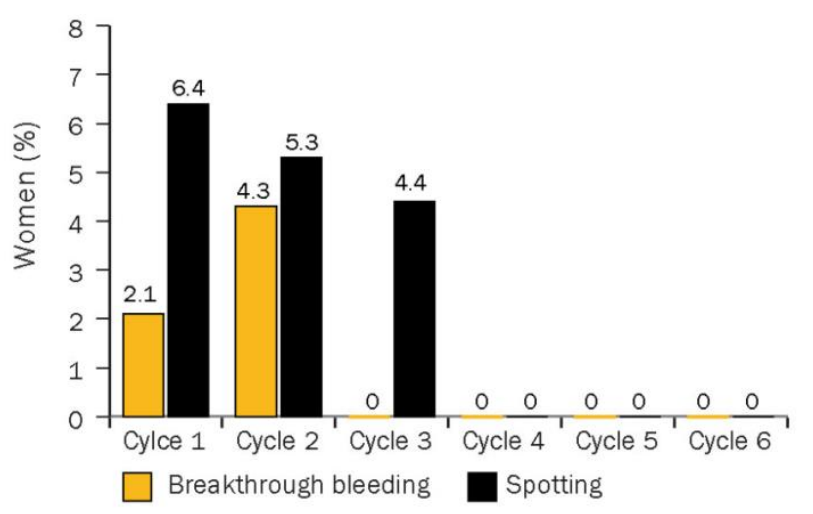

Figure 3: Percentage of breakthrough bleeding and spotting in each cycle.

\section{Highlights of the 24/4 regimen}

The highlights of the 24/7 COC regimen are summarised below: 12

1. Greater suppression of ovarian activity and follicular development with decreased risk of ovulation

2. Allows an increased contraceptive safety margin if pills are missed

3. Prevents hormonal fluctuations that help in reducing the hormone withdrawal symptoms during the HFI and improving quality of life

4. Beneficial in case of women who, for personal, cultural, or religious reasons, wish to have a monthly withdrawal bleed

\section{The Ultra-low-dose COC: Clinical evidence}

A COC with gestodene $60 \mu \mathrm{g}$ and EE $15 \mu \mathrm{g}$ offers the lowest hormonal dose in 24/4 treatment regimen. The clinical evidences regarding its efficacy and safety are discussed below.

\section{Contraceptive efficacy and cycle control}

An open-label, multicenter study evaluated the contraceptive efficacy, cycle control, and safety of 24/4 regimen of gestodene $60 \mu \mathrm{g}$ and $\mathrm{EE} 15 \mu \mathrm{g}$. A total of 1496 women were exposed to at least one tablet of COC and were included in the intention-to-treat population in this study. Three pregnancies were reported during 18,194 treatment cycles among 1424 women, with a pearl index of 0.21 . 136 women $(9 \%)$ did not take three or more active pills in at least one cycle. Furthermore, in $1837(10 \%)$ cycles of treatment, at least one treatment pill was missed by the participant. Overall, $72 \%$ of the cycles were normal, with proportion of normal cycles being $57 \%$ at treatment cycle 1 and improving to $73 \%$ by treatment cycle 19. A pattern toward reduction in incidence of breakthrough bleeding was noted with advancing treatment cycles. In $7 \%$ of the cycles, there was no withdrawal bleeding. ${ }^{18}$

Jaithithivit et al. conducted an open-label, noncomparative study to determine the cycle control, safety, and acceptability of six treatment cycles of 24/4 regimen of gestodene/EE $(60 / 15 \mu \mathrm{g})$ in 94 women. No pregnancy was reported during this study. The overall incidence of normal cycle was $86 \%$. Incidences of breakthrough bleeding and spotting were $2.1 \%$ and $6.4 \%$, respectively, in the first cycle, which then declined and were completely eliminated after the third cycle (Figure 3). Amenorrhea was noted in 1\%-4\% of women in the initial four cycles but was not noted in the later cycles. Furthermore, the length of withdrawal bleeding duration was also reduced from 4.5 days in the first cycle to 3.9 days in the sixth cycle. At the end of the study, 93.6\% of women were satisfied or very satisfied physically. Furthermore, $95.8 \%$ of women reported emotional satisfaction or high satisfaction. Given a choice, $91.5 \%$ of women wished to continue the regimen in future. ${ }^{19}$

Another prospective, open-label, multicenter study conducted by Barbosa et al. evaluated the efficacy of gestodene/EE 24/4 regimen for 6 months. Only one undesired pregnancy was reported while on treatment. Compared with baseline, there was a reduction in the mean cycle length. At the end of the sixth cycle, $49 \%$ of women had experienced a reduction in bleeding intensity compared with baseline. The incidence of breakthrough bleeding declined with the treatment cycles. ${ }^{20}$

\section{Safety}

The use of lower hormonal doses in COC has the potential to reduce common side effects associated with oral contraceptive use, such as nausea and breast tenderness. Gestodene/EE low dose 24/4 regimen was associated with lower incidence of estrogen-related adverse events, such as headache, breast tenderness, and nausea. $^{18}$

In the study by Jaithitivit et al., only minimal side effects were reported. Headache was the most commonly reported side effect, followed by nausea, vomiting, breast tenderness, and abdominal pain. During the six treatment cycles, dysmenorrhea was not reported. No change in body weight and blood pressure was observed during the study. ${ }^{19}$ In the study conducted by Barbosa et al. no alterations in body weight or laboratory evaluations were noted. Significant improvement in quality of life was observed, in terms of improvement in total Moos Menstrual Distress Questionnaire (MDQ) score. Further, the patients had a significant improvement in premenstrual complaints and symptoms. ${ }^{20}$

A systematic review has suggested that headache that occurs with the use of oral contraceptives in the early cycles improves or disappears with continued use. There 
was no evidence to support switching of one COC to another due to headache. ${ }^{21}$

Whether COCs exert a positive effect on bone mineral density (BMD) is debatable. A prospective, controlled, randomised study compared the effect of a low-dose $21 / 7$ regimen gestodene/EE $(75 / 20 \mu \mathrm{g})$ and an ultra-low-dose $24 / 4$ regimen gestodene/EE $(60 / 15 \mu \mathrm{g})$ on bone turnover and BMD in young, fertile women. The study reported a positive impact of both regimens, compared with control group, on bone turnover. There was significant reduction in pyridinoline and deoxypyrinidoline levels (markers of bone resorption) in both treatment groups from the third month of treatment. ${ }^{22}$

\section{Effect on haemostasis}

Cardiovascular side effects are the most important potential adverse events associated with OC use. The incidence of thromboembolic events is directly related to the dose of estrogen. The important reason for reduction of the estrogen dose in COCs is based on the evidence that COCs are accountable for the development of a hyperclottable state. ${ }^{23}$ A recent Cochrane review conducted that preparations containing lower doses of estrogen did not increase the arterial thrombotic risk, and the risk did not vary according to which progestogen type was used. ${ }^{23}$

A 12-month study evaluated the effect of 24/4 regimen of gestodene $60 \mu \mathrm{g} / \mathrm{EE} 15 \mu \mathrm{g}$ on cycle control and haemostasis in 58 healthy women (age 19-47 years Among the 20 women in whom haemostasis was evaluated, no changes in plasma fibrinogen concentrations or prothrombin fragment F112 were observed. There was a slight increase in thrombinantithrombin III complexes after 6 and 12 months of COC use. After a year of COC use, antithrombin III activity significantly increased. However, there was no effect on concentrations of tissue plasminogen activator and plasminogen activator inhibitor. The study concluded that, COC containing low doses such as $15 \mu \mathrm{g}$ EE do not affect haemostasis in healthy females. ${ }^{24}$

\section{Advantages of an ultra-low-dose COC}

While choosing a COC regimen for a woman, it is recommended to select one with lowest dose of estrogen and progestogen to provide good cycle control and effective contraception. The selected regimen should be well-tolerated. Reducing the dose of estrogen has been suggested in many women as a strategy to manage the common side effects such as nausea, breast tenderness, bloating, fluid retention, and headache. ${ }^{25}$ Considering the benefits of the ultra-low-dose COC, these may be suggested in women who experience side-effects associated with estrogen dose, such as nausea, breast tenderness, bloating and fluid retention, and headache. These may also be used in women for whom the lowest dose of estrogen is usually recommended, for instance in women who have had history of nausea, edema or hypertension in pregnancy; those with uterine fibroids, fibrocystic breasts, heavy menses or migraines. ${ }^{26}$

\section{CONCLUSION}

Medical writing support was provided by BioQuest Solutions Pvt. Ltd. and was funded by Pfizer.

Funding: No funding sources

Conflict of interest: Dr Meenakshi Ahuja was a paid consultant to Pfizer in connection with the development of this manuscript

Ethical approval: Not required

\section{REFERENCES}

1. Burkman R, Bell C, Serfaty D. The evolution of combined oral contraception: improving the risk-tobenefit ratio. Contraception. 2011;84:19-34.

2. De Leo V, Musacchio MC, Cappelli V, Piomboni P, Morgante G. Hormonal contraceptives: pharmacology tailored to women's health. Hum Reprod Update. 2016;22:634-46.

3. National Family Health Survey-3. 2005-06.

4. Bahamondes L, Bahamondes MV. New and emerging contraceptives: a state-of-the-art review. International Journal of Women's Health. 2014;6:221-34.

5. Megh M. A Review of Gestodene and Ultra-Low Dose Ethinyl estradiol in 24 Day Extended Regimen. Journal of the Association of Medical Women in India. 2015;VII; 14-20.

6. Guerra JA, Lopez-Munoz F, Alamo C. Progestins in combined contraceptives. J Exp Clin Med. 2013;5:51-5.

7. Goldstuck N. Progestin potency-assessment and relevance tochoice of oral contraceptives. Middle East Fertility Society Journal. 2011;16:248-53.

8. Stanczyk FZ, Hapgood JP, Winer S, Mishell DR Jr. Progestogens used in postmenopause hormone therapy: differences in their pharmacological properties, intracellular actions and clinical effects. Endocrine Reviews. 2013;34:171-208.

9. Stanczyk FZ, Archer DF. Gestodene: a review of its pharmacology, potency and tolerability in combined contraceptive preparations. Contraception. 2014;89:242-52.

10. London A, Jensen JT. Rationale for eliminating the hormone-free interval in modern oral contraceptives. Int J Gynaecol Obstet. 2016;134:8-12.

11. Read CM. New regimens with combined oral contraceptive pills moving away from traditional 21/7 cycles. Eur J Contracept Reprod Health Care. 2010;15(Suppl 2):S32-41.

12. Blake J. Evolving Strategies in the Dosing of Oral Contraceptives. The Canadian Journal of CME. 2009:35-40.

13. Willis SA, Kuehl TJ, Spiekerman AM, Sulak PJ. Greater inhibition of the pituitary-ovarian axis in oral 
contraceptive regimens with a shortened hormonefree interval. Contraception. 2006;74:100-3.

14. Klipping C, Duljkers I, Trummer D, Marr J. Suppression of ovarian activity with a drospirenonecontaining oral contraceptive in a 24/4 regimen. Contraception. 2008;78:16-25.

15. Hauck BA, Brown V. A primer on the hormone-free interval for combined oral contraceptives. Curr Med Res Opin. 2015;31:1941-8.

16. Sullivan H, Furniss H, Spona J, Elstein M. Effect of 21-day and 24-day oral contraceptive regimens containing gestodene $(60 \mu \mathrm{g})$ and ethinyl estradiol $(15 \mu \mathrm{g})$ on ovarian activity. Fertil Steril. 1999;72:115-20.

17. Sulak P, Scow RD, Preece C, Riggs MW, Kuehl TJ. Hormone withdrawal symptoms in oral contraceptive users. Obstet Gynecol. 2000;95:261-6.

18. Gestodene study group. The safety and contraceptive efficacy of a 24-day low-dose oral contraceptive regimen containing gestodene 60 microg and ethinylestradiol 15 microg. Eur J Contracept Reprod Health Care. 1999;4(Suppl 2):9-15.

19. Jaithitivit L, Jaisamram U, Taneepanichskul S. Cycle control, safety and acceptability of a new oral contraceptive containing ethinyl estradiol 15 micrograms and gestodene 60 micrograms. J Med Assoc Thai. 2012;95:630-5.

20. Barbosa IC, Filho CI, Faggion D Jr, Baracat EC. Prospective, open-label, noncomparative study to assess cycle control, safety and acceptability of a new oral contraceptive containing gestodene 60 microg and ethinyl estradiol 15 microg (Minesse). Contraception. 2006;73:30-3.
21. Loder EW, Buse Golub JR. Headache as a side effect of combination estrogen-progestin oral contraceptives: A systematic review. Am J Obstet Gyn. 2005;193(3):636-49.

22. Nappi C, Di Spiezio Sardo A, Acunzo G, Effects of a low-dose and ultra-low-dose combined oral contraceptive use on bone turnover and bone mineral density in young fertile women: a prospective controlled randomized study. Contraception. 2003;67:355-9.

23. Roach RE, Helmerhorst FM, Lijfering WM, Stijnen T, Algra A, Dekkers OM. Combined oral contraceptives: the risk of myocardial infarction and ischemic stroke. Cochrane Database Syst Rev. 2015;8:CD011054.

24. Fruzzetti F, Genazzani AR, Ricci C, De Negri F , Bersi C, Carmassi F. A 12-month clinical investigation with a 24-day regimen containing 15 microg ethinylestradiol plus 60 microggestodene with respect to hemostasis and cycle control. Contraception. 2001;63:303-7.

25. Sterwart M, Black K. Choosing a combined contraceptive pill. Aust Prescr. 2015;38:6-11.

26. Daniel S Seidman. Chapter 23. Ultra-low dose oral contraceptives. In: Contraception: Past, Present and Future. Editors: Bhalerao-Gandhi, Mukherjee B.

Cite this article as: Ahuja M, Pujari P. Ultra-lowdose oral contraceptive pill: a new approach to a conventional requirement. Int J Reprod Contracept Obstet Gynecol 2017;6:364-70. 